\title{
Non-structural Flood Protection and Sustainability
}

\author{
Zbigniew W. Kundzewicz, Research Centre for Agricultural and Forest Environment, \\ Polish Academy of Sciences, Poznan, Poland, and \\ Potsdam Institute for Climate Research, Potsdam, Germany
}

\begin{abstract}
In this article, flood protection is considered in the context of sustainability. On the one hand, floods destroy human heritage and jeopardize sustainable development, which can be defined as "non-decreasing quality of life." On the other hand, following the most common interpretation of sustainable development, one should not choose flood protection policies that could be rated by future generations as inappropriate options of flood defense. This is how several large structural flood defenses are often viewed. Non-structural measures are in better agreement with the spirit of sustainable development, being more reversible, commonly acceptable, and environment-friendly. Among such measures are source control (watershed/landscape structure management), laws and regulations (including zoning), economic instruments, an efficient flood forecast-warning system, a system of flood risk assessment, awareness raising, flood-related data bases, etc. As flood safety cannot be reached in most vulnerable areas with the help of structural means only, further flood risk reduction via non-structural measures is usually indispensable, and a site-specific mix of structural and non-structural measures seems to be a proper solution. Since sustainability requires thinking about the future generations, the climate change issue becomes important. Non-structural measures lend themselves well to application in climate change adaptation strategies. As uncertainty in the assessment of climate change impacts is high, flexibility of adaptation strategies is particularly advantageous.
\end{abstract}

Keywords: Flood protection, non-structural measures, sustainable development, sustainability criteria, risk management.

\section{Introduction}

Since the dawn of civilization, destructive floods have jeopardized settlements located in river valleys and plains. Despite developments in technology and extensive investments in flood control works, flood occurrences and the accompanying hardship and material damages are not decreasing: just the opposite. Currently, the global flood losses have grown worldwide to the level of billions of US dollars per year. According to the Red Cross, floods between 1971 and 1995 affected more than 1.5 billion people worldwide, including 318,000 who were killed and over 81 million left homeless (IFRCRCS, 1997).

Based on the data presented by Berz (2001), one could state that the number of great flood disasters (understood as those where the ability of the region to help itself is distinctly overtaxed) has grown considerably worldwide (Figure 1), for reasons discussed later. The number of great flood disasters in the nine years between 1990 and 1998 was higher than in the three-and-half decades between 1950 and 1985.

In the 1990s, there were two dozen flood disasters in which either the material losses exceeded one billion US dollars or the number of fatalities was greater than one thousand, or both (Kundzewicz and Takeuchi, 1999). In a storm surge flood in Bangladesh in April 1991, 140,000 people lost their lives, while record-high material losses were recorded in China in the 1996 and 1998 floods: US\$30 billion and US $\$ 26.5$ billion, respectively.

The vulnerability of societies grows as they become wealthier and more exposed - technology helps populate more "difficult" areas. Vulnerability to floods can be regarded as a function of exposure and adaptive capacity (IPCC, 2001a). Both have been increasing (and are likely to continue to rise). However, since exposure grows faster than adaptive capacity, the vulnerability increases too. The rise in exposure has been caused by human activity, e.g., by elimination of storage, wetlands, and natural vegetation and by encroachment of infrastructure in floodplains. According to Newson (1997), one-sixth of all urban land in the US lies within the 100-year flood area. Around 10 percent of population of such countries as the US and UK live within the 100-year flood area, while in Bangladesh, this portion is much higher. The 1998 flood inundated over two-thirds of the area of Bangladesh. In addition to direct human impacts, climate change is also likely to contribute to the increase in flood risk.

Floods are natural events and will continue to occur in the future - one can never achieve complete safety. Yet, the flood risk can be seriously restricted if an appropriate preparedness system is built. 


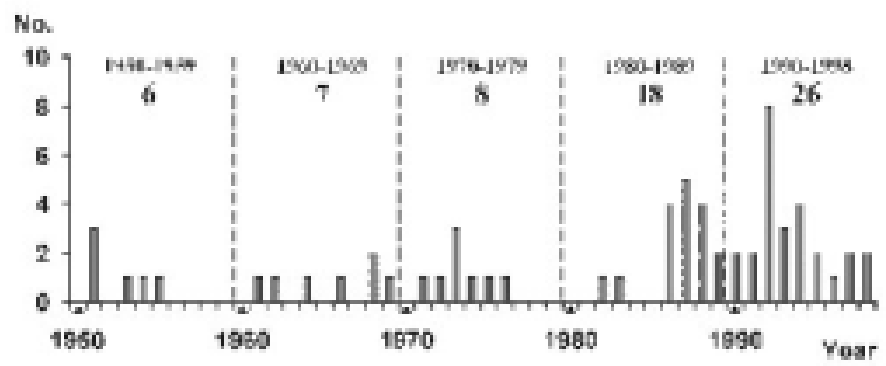

Figure 1. Number of great floods worldwide in time period 1950 to 1999.

\section{Structural and Non-structural Flood Protection Measures}

There exists a roster of strategies for reducing flood losses by flood protection and management shown in Box 1 , together with examples of particular activities.

It is common to assume that flood protection measures can be structural (hard) or non-structural (soft). Structural defenses have a very old tradition, as dams and dikes have been built for at least four thousand years. Nearly all floodplain areas in Hungary are protected by river dikes. Constructing reservoirs where the excess water can be stored allows a regulated temporal distribution of streamflow with the natural peak flow reduced.

It is quite a common interpretation that the term "structural" refers to large-scale defences, such as dikes, dams, and flood control reservoirs, diversions, floodways, etc., and to channelization improving channel conveyance capacity (widening, deepening, realignment, bank protection, etc.). Then, distributed, small-scale, structural approaches, such as flood proofing, are regarded as soft approaches.

A sample of non-structural flood protection measures include: source control (watershed/landscape structure management), laws and regulations, zoning, economic instruments, an efficient flood forecast-warning system, a system of flood risk assessment, awareness raising and improving information, flood-related data bases, etc.

\section{Flood Forecasting and Warning}

Flood forecasting and warning is a very important nonstructural flood protection measure. Thanks to flood forecasting and warning systems, it is possible to save human lives. Forecasting, based on mathematical modeling, allows experts to convert the information on the past-topresent rainfall, status of moisture, and snow cover into a river flow forecast (discharge, stage, and inundated area for a future time horizon). For small catchments and flash floods, a time lag between an intense precipitation and the flood peak is very short. Therefore deployment of radar and quantitative precipitation forecast is necessary. Propagation of a flood wave in a large river may take several weeks, allowing for ample time for response to flood forecast. There are many attempts to improve the forecast accuracy and to extend the time horizon for a meaningful forecast. One challenging avenue is to make use of atmospheric-oceanic-hydrological links. Accurate forecasts should be translated into reliable warnings, broadly and effectively disseminated to the communities at risk so they can take adequate loss-reducing actions.

Box 1. Strategies for Flood Protection and Management

(1) modify susceptibility to flood damage

legislation, land-use planning and management, zoning - delineation of areas where certain land uses are restricted or prohibited, development control of flood hazard areas leaving floodplains with low-value infrastructure, e. g. riparian forests which are subject to frequent flooding, buy-out of land and property located in floodplains - stimulating relocation, flood proofing (by elevation, barriers, or sealing i. e. water-proofing of parts of buildings or individual appliances), disaster contingency planning, flood forecasting and warning systems, flood insurance schemes, awareness raising: improving information and education on floods and on actions to take in a flood emergency, community self-protection teams

(2) modify flood waters

flood defence infrastructure: dams and flood control reservoirs, flood dikes, diversions, floodways, improvement of channel capacity to convey a flood wave, enhancing source control via watershed management, enhancing storage - floodplains and wetlands, polders and washlands, enhancing infiltration - permeable pathways and parking lots, etc., vegetation management (afforestation, cropping pattern avoiding bare soil during precipitation season), terracing and contour ploughing.

(3) modify impact of flooding

detection of the likelihood of flood formation, forecasting of future river stage / flow conditions, warning issued to the appropriate authorities and the public on the extent, severity and timing of the flood, dissemination of warning, response by the public and the authorities, evacuation, financial aid (insurance claims, loans, tax deduction, debt reduction), relief for those affected by the disaster, reconstruction of damaged buildings, infrastructure and flood defences, post-flood recovery and regeneration of the environment and the economic activities in the flooded area, review of the flood management activities to improve the process and planning for future events (links to (1) and (2))

In Italic: lumped, large-scale structural measures. 


\section{Watershed Management}

Source control modifies the formation of floodwater. This concept belongs to a broader category of watershed management including land use and soil conservation to minimize surface runoff, erosion, and sediment transport by terracing and contor ploughing, vegetation cover management and afforestation. The idea of "catching water where it falls" is implemented by such measures as enhancing infiltration, reducing impermeable area, and enhancing storage by ponds or artificial storages (Kundzewicz and Takeuchi, 1999). Enhancing retention counteracts such adverse effects of urbanization as decrease in storage potential, growth of flood peak, and decrease in time-topeak of a hydrograph. Watershed management should also include increase of storage in the river system (floodplains, polders, washlands).

\section{Insurance, Aid, and Post-flood Recovery}

Existence of appropriate schemes of insurance, or distribution of risks and losses over a large number of people and long time, and disaster aid, or capacity to compensate losses not covered by insurance, are important components of flood preparedness. These mechanisms are needed in order to help flood victims recover after losses.

Post-flood recovery is often less spectacular than actions during flood, as national leaders and the media who have left the natural catastrophe area become disinterested. Disaster aid, based on voluntary solidarity contribution, national assistance, and international help is essential to restore livelihood and employment of survivors.

\section{Zoning and Relocation}

A saying goes that if people build in a floodplain, there is no solution. Certainly precautionary measures, such as zoning and regulation of floodplain development, are advantageous. However, if endangered locations have already been developed, a remedy is that humans and infrastructure move out of harm's way. After the Great Flood of 1993, the US Interagency Floodplain Management Review Committee (IFMRC, 1994; Galloway, 1999) recommended that the administration should fund acquisition of land and structures at risk from willing sellers in the floodplain. The number of families relocated from the vulnerable floodplain locations in the Mississippi Basin is of the order of 20,000 (Galloway, 1999), and continues to grow.

However, despite the encouraging example from the US, permanent evacuation of floodplains is unthinkable in other areas, such as Bangladesh - a densely populated and low-lying country, virtually the most flood-prone country of the globe. The nation of Bangladesh, indeed, must live with floods. Most of the country is constituted by floodplains whose soil fertility depends on flood visits. New flood embankments, even if they were affordable, would take much of this highly demanded land. Thus, the options include reinforcing the existing structural defenses and enhancing non-structural measures, such as forecast-warning system and awareness raising.

In the global scale, an essential self-sustaining measure is benign population growth management, attainable by the family planning and fertility reduction through improving living standards. If there were less demographic pressure, floodplain settlement would be more constrained.

\section{Sustainable Developments - Notions and Interpretation}

Although the notion of "sustainable development" has been broadly used nowadays, there is no common understanding of this term, and the concept may still mean different things to different people. The term serves a variety of targets, being used and abused as a convenient argument to justify, support, or criticize actions (or lack of actions), decisions, etc. Because of ambiguity, it is not possible to delineate the borders between "sustainable" and "nonsustainable" in a unique way, though one can demonstrate examples that can be rated as clearly sustainable or clearly non-sustainable.

There exist a number of alternative definitions of sustainable development, a sample of which are presented in Box 2.

Sustainable development embraces a blend of objectives, being economically feasible, socially acceptable and environmentally sound (Takeuchi et al., 1998). A sample of specific objectives include: in the economic area growth, efficiency and equity-fairness, in the social areaparticipation, empowerment, culture, tradition, and institutional development - and in the environmental area - ecosystem health and integrity, conservation of nature, respecting the carrying capacity, and biodiversity. In all these areas, the notion contains resilience to surprise or shock, therein to climate variability and change, and to violent abundance of destructive floodwater.

In order to monitor the progress towards sustainable development one needs a set of suitable criteria and indicators assisting to steer action, to make decisions and to

Box 2. A Sample of Definitions of Sustainable Development

- fulfilling the development needs of the present generation without compromising the ability of future generations to meeting their own needs (WCED, 1987);

- improving the quality of human life (attaining non-decreasing human welfare over time) within the carrying capacity of supporting ecosystems (IUCN, 1991);

- living on the "interests" from the Earth "capital" without depleting the possessions inherited from former generations (cf. Kundzewicz et al., 1987);

- keeping dynamic equilibrium of the Earth system over a long (theoretically - infinite) time;

- property of the system whose essential features remain within satisfactory domain over a long time;

- development minimizing probability of future regret for decisions taken today. 
increase focus on sustainable development. Yet, despite numerous proposals (Takeuchi et al., 1998) and some progress achieved, there exists no commonly accepted set of criteria and indicators.

\section{Flood Protection in Sustainability Context}

It is worthwhile to view flood hazard mitigation in a broader context, as a part of a general sustainable development strategy.

A common interpretation of sustainable development is that civilization, wealth (human and natural capital), and environment (built and natural) should be relayed to future generations in a non-depleted condition. That is, civilization and wealth should be protected, inter alia, from devastating floods, which destroy cultural landscapes and undermine sustainable development by breaking continuity.

Another aspect of the definition of sustainable development is that, while flood protection is necessary for the present generation to attain a fair degree of freedom from disastrous events, it must be done in such a way that future generations are not adversely affected. Brooks (1992) stated that a minimum requirement for general sustainability is that "one does not paint oneself into a corner from which retreat is either impossible or unaffordable." According to the UK Environment Agency (1998), sustainable flood defense schemes should "avoid as far as possible committing future generations to inappropriate options for defence." Some flood protection infrastructure has been criticized in the context of sustainable development for closing options for future generations and introducing disturbances in ecosystems (Takeuchi et al., 1998).

Soft measures, which do not involve large structural components, can be rated as more flexible, less committing, and more sustainable than hard measures; yet the latter may be indispensable in particular circumstances. Indeed, non-structural measures alone cannot provide a satisfactory solution in such flood-vulnerable countries as Bangladesh and Japan. Strategies for major cities along large rivers in Japan include protection by high-cost structural measures: "super levees" of 300 to 500 m width (Kundzewicz and Takeuchi, 1999), which protect considerable wealth accumulated in urban areas of Japan. On the other hand, small-scale structural measures, such as flood proofing, building codes, extending permeable areas etc., are regarded as sustainable.

In order to assess sustainability of a flood protection scheme, one needs adequate criteria and indicators. Simonovic (in Takeuchi et al., 1998) proposed four general, conceptual, and self-explanatory criteria for evaluation of sustainability: reversibility, fairness, risk, and consensus, which are all relevant in the context of flood defenses. One could add to these criteria a measure of efficiency and synergism. For example, a multi-purpose reservoir may also have a number of functions related to sustainability: flood protection, water supply, waterpower, navigation, etc.

A checklist, devised by the Delft Hydraulic Laboratory (Loucks, 1994), embraced five main criteria, which are subsequently divided into four sub-criteria each. The main criteria, which can be used to evaluate flood protection systems, are:

- socio-economic aspects and impacts on growth, resilience, and stability;

- use of natural and environmental resources including raw materials and discharge of wastes within the carrying capacity of natural systems;

- enhancement and conservation of natural and environmental resources;

- public health, safety, and well being; and

- flexibility and sustainability of infrastructural works, management opportunities for multi-functional use, and opportunities to adapt to changing circumstances.

Examples of quality indices which could be used for comparing flood protection measures in the sustainability context may relate to socio-economic and financial feasibility, related investment and operational costs, degree of intervention in the natural regime, stress to ecosystems and humans, use of energy and raw materials, safety, risk and reliability issues, and opportunities for reversibility (flexibility) and rehabilitation (Kundzewicz, 1999). Table 1 shows a roster of components of flood preparedness system and an assessment of their compliance with the spirit of sustainable development.

Gardiner (1995) compared options of flood defense and assessed their performance from the sustainability viewpoint. He suggests using four groups of criteria, which relate to (1) global environment (resilience to climate change, energy efficiency, biodiversity), (2) inter-generational equity (retention of strategic adaptability/future options), (3) natural resources (quantity and quality of surface water and groundwater, wildlife habitat), and (4) local environment quality (morphological stability, landscape and open land, recreation, amenity and enhancement of river environment). Gardiner (1995) rates source control as very good, while channelized river is rated as bad to very bad according to all criteria. He also noted that source control conserves resources, buffers systems from possible climate change impacts, promotes biodiversity by retaining water, improves self-sufficiency, and recharges groundwater.

Looking at recent specific examples of floods (e.g., Kundzewicz et al., 1999), it is clear that more attention should be paid to non-structural flood protection measures. The importance of non-structural measures is also illustrated by the power of adaptation. Where a flood visits a place twice in a short time period (e.g., on the Rhine in December 1993 and January 1995), losses during the second flood occurrence are typically far lower than during the first occurrence. The riparians are definitely taking a lesson from the first flood incidence. 
Table 1. Compliance of Components of Pre-flood Preparedness with the Spirit of Sustainability

Construction of large physical flood defence infrastructure

Zoning, development control within the floodplains

Source control, land-use planning and watershed management

Flood forecasting and warning system

Flood proofing

Disaster contingency planning and maintenance of preparedness of community self-protection activities

Installation of insurance scheme

Capacity building, improving flood awareness, understanding and preparedness
$\mathrm{L}$ to $\mathrm{M}$

$\mathrm{M}$ to $\mathrm{H}$

$\mathrm{M}$ to $\mathrm{H}$

$\mathrm{H}$

L to $\mathrm{H}$

$\mathrm{H}$

L to $\mathrm{H}$

$\mathrm{H}$

Notation: $\mathrm{H}$ - high, $\mathrm{M}$ - medium, $\mathrm{L}$ - low.

\section{Information for Sustainable Development}

Hydrological information is indispensable for building flood protection systems. This relates to both flood protection infrastructure (dikes, dams, reservoirs, spillways, floodways, canals, etc.) and non-structural approaches such as zoning, insurance, legislation, etc.

Water storage reservoirs are basic components of water management, serving multiple purposes including flood protection. Hydroclimatic information plays a significant role in both reservoir design and operation. In the design phase, estimating of the necessary reservoir capacity and the size of the spillway must be done based on the available hydrological data. Availability of long time series of records is necessary to detect slow (e.g., caused by climate change or land-use change) tendencies that can significantly influence flood protection. Finally, during a flood, the need for real-time information arises for flood forecasting and warning.

In order to minimize the chances of non-satisfactory design, construction, or operation of water systems, an adequate level of basic data collection is required. The basic hydrological network should, therefore, provide a level of hydrological information that would preclude gross mistakes in decision-making related to freshwater. Therefore, hydrological observations should be recognized as an essential component of sustainable development and management of water resources (Kundzewicz, 1997; 2001).

The numbers of hydrological stations in operation, as reported by the WMO Member countries, are impressive. According to WMO (1995), there are nearly 200,000 precipitation gauges operating worldwide. At over 64,000 stations, river flow is being observed and at nearly 38,000, the water level. However, these comforting global totals are misleading - the hydrological observation networks are not uniformly distributed, and there is an acute lack of data in some regions. Furthermore, due to financial stringencies in many countries, hydrological services and data collection networks are shrinking and are not able to provide the information needed for flood protection.

Given that important decisions need to be made under vast uncertainty, it is rational to try and reduce this uncertainty by collecting observational data characterizing the natural and human-influenced processes and the state of the environment. Acquisition of data and information undoubtedly serves sustainable development by enhancing capacity building for better preparedness in the future.

\section{Awareness Raising}

Improving information about floods is badly needed for awareness raising and enhancing the consultative process, which leads to a flood protection strategy. Only informed stakeholders can make rational decisions about choice of strategies of flood protection, in cost-benefit framework; with the account of sustainability issues.

Yet, misconceptions and myths about floods and flood protection are deeply rooted in the society - the general public, politicians and decision-makers alike. It is of utmost importance to dispel and to rectify misconceptions, such as those collected in Box 3. Apart from misconceptions, there are counter-productive "principles," valid throughout political and social systems, such as Klemes'

Box 3. A Sample of Common Misconceptions about Floods and Flood Protection

Flood protection systems, which are in place, warrant absolute safety. If levees and dams cost that much money, they must withstand greatest floods! This is false!

Floods occur at semi-regular intervals. This misconception results from a common layman's interpretation of the notion of "100-year flood". In consequence, many naively believe that once a 100-year flood has occurred recently, the next deluge will not come in a human lifetime. (A separate misconception is a deep belief that one can reliably estimate what a 100 -year flood would be).

Stationary world: geophysical processes in the future will be similar to those in the past. Having lived in a place for a while one can get a feeling of what can be expected. Some find it hard to appreciate that a flood may come, which exceeds by far all the events on record.

Floods do not happen at all rivers. Certainly, they happen frequently in "wet" areas, such as Bangladesh, etc. It is less appreciated that destructive floods also hit arid and semi-arid zones, where the population is unprepared. 
rule of hydro-illogical cycle. Flood occurrence triggers high expenditures on flood protection. Yet, memory fades and after some time without flood, the willingness to pay drastically decreases. How can this truth be communicated to the electorate and decision-makers whose term of office is short?

Efficient actions aimed at awareness raising are of vast importance for a flood preparedness system. Among over 50 fatalities of the 1997 flood in Poland, many could have been avoided if the awareness was better. Most flood fatalities in the US are related to vehicles whose drivers underestimate the danger.

The role of media in awareness raising and information spreading is worthy of interest. The freedom of press does not always match responsibility. A particularly bad example is embedding flood mitigation into a political campaign (Kundzewicz et al., 1999).

Apart from collecting data and building flood-related databases, information can be generated by modeling. Mathematical models do not only serve forecast systems. They are indispensable for improving general understanding - simulation of events, analyzing efficiency of policies and measures, what-if studies, etc. Flood risk mapping conveys valuable spatial messages. Yet, in a number of cases, such maps, solicited by authorities, have not been disseminated - the consequences would be unbearable for the ruling powers.

\section{Learning from the Past}

Flood losses worldwide have been increasing with time. It has been so for a number of reasons, such as myriads of locational decisions related to settlements and economic development of flood-prone areas (floodplains, coast). Floodplains indeed attract development due to their flatness, high soil fertility, proximity to water and availability of construction materials. Human pressure and shortage of land cause the tendency of encroaching into floodplains, and investing in infrastructure there. In such a way, much of the natural flood storage volume is lost, ecosystems are devastated and riparian wetlands destroyed.

Urbanization has adversely influenced the flood hazard in many watersheds. Increases in the portion of impervious area (roofs, yards, roads, pavements, parking lots, etc), deforestation, and regulation of watercourses result in faster and higher peaks of runoff responses to intensive precipitation. In mountainous areas, development extends to hilly slopes, which are endangered with landslide and debris flows. High vulnerability to flooding accompanies urban squatting.

Important discussions of strategy of flood protection dates back to the mid- $19^{\text {th }}$ century in the US (Williams, 1994), when the US Congress looked into the problem of the Mississippi floods. One expert recommended that large areas of the Mississippi floodplains be used as flood storage and overflow areas, but the US Congress heeded an- other expert who recommended embanking the Mississippi River in a single channel isolated from its floodplain. This decision has largely influenced flood protection policy in the US and elsewhere, leading to transformation of rivers and reduction of wetlands. Thomas (1995) noted that 54 percent of the wetlands area in the USA have been drained, primarily for agricultural use. In 1936, the US federal government assumed primary responsibility for flood damage reduction across the nation and over the next 40 years embarked on a multi-billion dollar program of structural defences (Galloway, 1999).

In the absence of well agreed upon quantitative criteria and indicators measuring sustainability, a retrospective view is useful. What heritage of the past is not liked by our generation? What elements of flood protection systems are being criticized? Which acts of past generations are regretted by the present generation?

Certainly changes leading to aggravating flood risk are perceived as negative. In some locations, people regret that levees were built and low-lying areas developed. Now the issue of river re-naturalization may come about. Some large reservoirs, whose construction required inundation of large areas and/or displacement of high number of people, do not match the principles of sustainable development. Studies on decommissioning reservoirs are being made and in a few cases indeed decommissioning has taken place (Takeuchi et al., 1998).

When looking back into past developments, one often finds one-sided arguments supporting a decision, with important aspects neglected. This was, on the one hand, due to lack of knowledge and understanding and, on the other hand, due to value judgment changing in time.

\section{Climate Impact Assessment}

The process of river flow has been heavily influenced by direct changes caused by humans, discussed earlier. Humans may have caused other changes in an indirect way, e.g., through enhanced emissions of greenhouse gases resulting in the global warming and the related effects.

The possibility of climate variability and change may add another dimension to the sustainability notion. Sustainability refers to the future (prospects of future generations), hence climate changes are of substantial concern. There are a number of cases when the recent behavior of time series of hydrological variables largely differed from the historical patterns. Many scientists attribute a part of these changes to the anthropogenic impact on the natural climatic system: the growing greenhouse effect and the corresponding climate change. Increasing severity of extreme events has been detected recently in some (but not all) locations, and some experts have reported considerable local shortening of recurrence intervals of a given flood magnitude. Insurance industry is becoming concerned with the increase of compensations following natural water-related disasters - existing infra- 
structure may not guarantee the adequate level of protection.

However, it is generally difficult to find a gradual change (e.g., related to climatic impacts) in the behavior of the extremes of river flow amidst strong natural variability. Global temperature rise accelerates the hydrological cycle. Runoff is a difference between precipitation and evapotranspiration (whose annual means have been increasing and are projected to continue to increase over most areas), so the net effect on their difference is not intuitively clear. In order to detect a weak, if any, climate change component, it is necessary to eliminate other influences, by using data from baseline river basins.

Apart from the inherent complexity of the very issue of detecting a greenhouse component in flow records, there are serious problems related to the data with which to work, and also to the methodology of detection (Kundzewicz and Robson, 2000; Radziejewski et al., 2000). Even if the data are perfect and abundant, it is worthwhile to re-state a tautology: extreme events are rare. They do not happen frequently, so even having an instrumental record extending over a century, one still deals with a small sample of truly extreme floods of most destructive power (Kundzewicz and Robson, 2000).

\section{What Have Observed Data Been Telling Us?}

It is a well-established fact that the effects of human pressure have aggravated flood risk. Development of lowlying areas at risk has continued and the storage capacity of catchments has decreased. As noted by Bronstert (1996), urbanization is particularly influencing small or middle size floods - the urbanized area in West Germany more than doubled from 6 percent in 1950 to approximately 13 percent in 1995.

Is there a climate change signature in flood data? Existing prognostications announce increasing frequency and severity of floods in the future warmer world with accelerated hydrological cycle. A question can be posed: how do these predictions fare in the context of the evidence provided by the already observed data?

According to IPCC (2001b), instrumental records of land surface precipitation have shown an increase over many areas. Furthermore, pronounced increases in heavy and extreme precipitation events have been observed, arising from a number of causes, e.g., changes in atmospheric moisture and large-scale storm activity. Observations confirm that atmospheric moisture is increasing in many places, at a rate of about 5 percent per decade in the US (Trenberth, 1998). Increased atmospheric moisture contents favor more intensive precipitation events thus increasing the risk of flooding.

Trends in the $20^{\text {th }}$ century show marked increase of precipitation, especially in winter, in much of Europe, but particular in the north and northeast. There have been several national studies corroborating these findings. For instance, there is evidence that the frequency of extreme rainfall has increased in the UK (IPCC, 2001a), and a greater proportion of precipitation is currently falling in large events than in earlier decades (Osborn et al., 2000). Karl et al. (1995) noted that within the United States, the proportion of total precipitation contributed by extreme oneday events increased significantly during the $20^{\text {th }}$ century. The incidence of intensive precipitation events has steadily increased at the expense of moderate events.

As far as river runoff is concerned, there have been a plethora of studies of time series at a single stream gauge reported in the literature. Several reports of significant changes detected in flow records at a single gauge encouraged researchers to extend the analysis into a spatial domain to check whether or not a pattern observed at a point has been reproduced in the neighboring locations. Yet, it would be a gross oversimplification to say that, in general, floods have exhibited growing trends worldwide. Only some series show a significant trend and out of those only some (typically more than half) feature a growing trend. It is not uncommon that neighboring gauges behave in a different way (due to other, non-climatic factors), not necessarily in tune with gross climate-related prognostications.

A sample of the results from analyses of long time series of data reported in literature is presented in Table 2. After IPCC (2001a), the costs of extreme weather events have exhibited a rapid upward trend in recent decades and yearly economic (inflation-adjusted) losses from large events have increased ten-fold between 1950s and 1990s. The insured portion of these losses has grown even stronger. Demographic and socio-economic trends are increasing society's exposure to floods and part of the observed upward trend in losses is linked to socio-economic factors, such as increase in population, wealth, and developing settlements in vulnerable areas, but these factors alone cannot explain the observed growth in losses. As stated in IPCC (2001a), a part of losses is linked to climatic factors, such as the observed changes in precipitation and flooding events. The growth in losses caused by non-weather-related natural disasters has been far lower than for weatherrelated extreme events.

Pielke and Downton (2000) studied the rates of change in flood characteristics and socio-economic indicators in the US in the time period from 1932 to 1997 . They found that the total annual flood damage, adjusted for inflation, has grown in the average at the rate of 2.92 percent per year, which is greater than the population growth rate $(+1.26$ percent $)$ and tangible, inflation-adjusted, growth in wealth per capita $(+1.85$ percent $)$.

An important change has been observed in seasonal characteristics of flow data. River flow regimes, such as temporal distributions of flow, have considerably changed. In much of Europe, high flows that come earlier in the year due to earlier snowmelt (sometimes in winter rather than spring) and lower snow cover may reduce the spring 
Table 2. A Sample of Findings on Trends in Existing Flow Data Reported in Literature.

\begin{tabular}{|c|c|c|c|}
\hline Source & Location & Time interval & Finding \\
\hline Engel (1997) & Rhine at Cologne & 1890 to 2000 & Positive trend in annual maxima. \\
\hline Nobilis \& Lorenz (1997) & Austrian rivers & $\begin{array}{l}1952-1991 \\
\text { shorter periods }\end{array}$ & $\begin{array}{l}\text { Only in a portion of cases (from } 4.3 \% \text { to } 31.5 \% \text { ), a signifi- } \\
\text { cant trend was detected, therein, more examples of positive } \\
\text { trend }(64.3 \%) \text { than of negative trend }(35.7 \%) \text {. }\end{array}$ \\
\hline Gilvear \& Black (1999) & River Tay in Scotland & $\begin{array}{l}1988 / 9 \text { versus } \\
1996-1997\end{array}$ & Growth of flood-induced embankment failures. \\
\hline Mansell (1997) & $\begin{array}{l}\text { Four catchments } \\
\text { in Scotland }\end{array}$ & Last 30 years & $\begin{array}{l}\text { General increase in river flow, significantly stronger than the } \\
\text { increase in rainfall over the same period. }\end{array}$ \\
\hline Robson \& Reed (1996) & $\begin{array}{l}\text { Ca. } 600 \text { stream gauges } \\
\text { in the UK }\end{array}$ & $\begin{array}{l}\text { Long data series } \\
\text { (from } 15 \text { to over } \\
100 \text { years) }\end{array}$ & $\begin{array}{l}\text { Some regional features visible in the results. More incidences } \\
\text { of increased flooding than decreased flooding, particularly in } \\
\text { Scotland and in South East of England. }\end{array}$ \\
\hline Olsen et al. (1999) & $\begin{array}{l}\text { Rivers: Upper } \\
\text { Mississippi, Lower } \\
\text { Missouri and Illinois }\end{array}$ & $\begin{array}{l}\text { Long series } \\
\text { (up to nearly } \\
120 \text { years) }\end{array}$ & $\begin{array}{l}\text { In many gauges, large and statistically significant upward } \\
\text { trends were detected. }\end{array}$ \\
\hline Lins \& Slack (1999) & $\begin{array}{l}\text { Ca } 400 \text { stream gauges } \\
\text { the conterminous U. S. }\end{array}$ & $\begin{array}{l}30-, 40-, 50-, 60- \\
70-, \text { and } 80-\text { year } \\
\text { periods, all ending } \\
\text { in } 1993\end{array}$ & $\begin{array}{l}\text { For all, but the highest quantiles, streamflow has increased } \\
\text { across broad areas of the US. These results were summa } \\
\text { rized as "getting wetter, but less extreme." }\end{array}$ \\
\hline
\end{tabular}

snowmelt floods. Milder winters lead generally to thinner ice cover, so ice-jam floods are not a major problem anymore in much of Europe.

Search for links of hydrological extremes with climatic variability (oscillations in the oceanic-atmosphere system, such as El Niño-Southern Oscillation (ENSO), North Atlantic Oscillation (NAO), and Arctic Oscillations (AO), is a challenging study area The frequency and intensity of ENSO have been unusual since the mid 1970s, as compared with the previous 100 years, in the context of the instrumental record. The warm phase of ENSO episodes during which intensive precipitation (causing floods) occurs more frequently in some regions has become more persistent and intense (IPCC, 2001b).

The global average sea level rose by 10 to $20 \mathrm{~cm}$ during the $20^{\text {th }}$ century, partly due to the thermal expansion of ocean water (steric rise) and the widespread loss of land ice associated with the $20^{\text {th }}$ century warming. The average rate of the sea level rise in the $20^{\text {th }}$ century was larger by an order of magnitude than the average rate over the last 3,000 years (IPCC, 2001b). Rise of the mean state of the sea level clearly impacts on extremes. Increased frequency of flooding in Venice accompanied $30 \mathrm{~cm}$ relative sea level rise in the $20^{\text {th }}$ century (IPCC, 2001a).

\section{Extreme Events - Projections for the Changing Climate}

A significant portion of the increase of flood hazard has been caused by direct human pressure, which will continue to be active in the future. However, there are also several climate change related mechanisms, which may significantly influence flood characteristics. Characteristics of extreme climatic phenomena related to floods, can change in the future, in the light of scenario analyses (IPCC, 2001a; 2001b). Among foreseen climate-related impacts relevant to floods are: increased magnitude of precipitation events of high intensity in many locations, more frequent wet spells in mid/high latitude winters, more intense mid-latitude storms, and more El Niño-like mean state of ENSO. Some models show increase of mean and peak intensity of precipitation and peak wind intensity of tropical cyclones (IPCC, 2001b).

Arnell (1999) compared projected changes in precipitation across the world land areas. In all six scenarios considered, precipitation is expected to increase, globally, depending on the scenario: from 0.6 to 3.4 percent in the 2020 s and from 2.1 to 7.5 percent in the 2080 s, as compared to the climatological standard normals, 1961 to 1990. Arnell (1999) also noted an amplification effect in change in annual runoff, versus annual rainfall. He showed that many regions would feature considerable changes in 10year return period maximum monthly runoff, noting increases in such areas as the northwest north America and in East Asia.

Regional precipitation scenarios for winter developed under the ACACIA project (Parry, 2000), for the ACACIA A2-high scenario, show increases across most of Europe, while the median of annual precipitation grows in particular grids by up to 14 percent in 2020 s, through up to 35 percent in 2050s and up to 53 percent in 2080 s, though results of models vary widely. Wetter winters are pre- 
dicted throughout the continent, with two regions of highest increase: the Northeast and northwest Mediterranean coast, including northern Italy.

Climate change is likely to increase the risk of river flooding and loss and damage generally in Europe. In particular, winter flood hazard is likely to rise for many catchments under many scenarios.

\section{Sea Level Rise}

Perhaps the sea level rise is the most important single climatic factor, which contributes to increasing (coastal) flood risk. A change in the mean level may exert significant impacts on the extremes and higher peak wind intensities may contribute to increasing severity of coastal flooding. Needless to say, sea level rise itself is already a dangerous occurrence, which may lead to permanent inundations (including disappearance of small and low-altitude islands) and the need of massive relocation.

Estimates of flood exposure and incidence for Mediterranean coasts in 1990 s to the 2080 s, given in IPCC (2001b), foresee a sea-level-rise driven increase of the average number of people experiencing flooding by 260 to 120,000 percent, under assumption of no adaptation.

\section{Conclusion: Living with Floods}

Since a flood protection system guaranteeing absolute safety is an illusion, a change of paradigm is needed. It is necessary to live with the awareness of the possibility of floods and to accommodate them, rather than to try, in vain, to eradicate them (Kundzewicz and Takeuchi, 1999).

Building flood risk consciousness among the public is of paramount importance. No matter how high a designsafe flood is, there is always a possibility of having a greater flood, inducing losses. Should dikes be designed to withstand a 100 -year flood or perhaps a 500 -year flood? The latter solution would give a better protection, being far more costly. Yet, it may still turn out to be insufficient if a 1,000 -year flood arrives.

Despite the critiques of structural flood protection measures like dams and levees, they are absolutely needed to safeguard existing developments, in particular in urban areas. Reinforced dikes, or super-dikes, play an important part in flood protection of urban areas in Japan (Kundzewicz and Takeuchi, 1999). An effective flood protection system is generally a mix of structural and nonstructural measures. Those latter approaches better conform to the spirit of sustainable development.

Discussion is offered of climate-change impacts, pertaining both to the past data and of scenarios for the future. The general statement that high floods are becoming more frequent is supported by several studies and is being challenged in other analyses. A regional change in timing of floods has been observed in many areas, with increasing late autumn and winter floods in Europe. This has been a robust result. Yet, intensive and long-lasting precipitation episodes happening in summer have also led to disastrous recent flooding (e.g., the Odra/Oder deluge in 1997; Kundzewicz et al., 1999; Kundzewicz and Kaczmarek, 2000).

It is difficult to disentangle the direct anthropogenic and climatic component in the flood data subject to strong natural variability and influenced by man-made environmental changes: urbanization, deforestation, human occupying hazardous areas, reduction in storage capacity, etc.

The future change of flood risk may be complex. In many places flood risk is likely to grow, due to a combination of anthropogenic and climatic factors. Yet, quantification of flood statistics is difficult and subject to high uncertainty. As stated in IPCC (2001b), "[t]he analysis of extreme events in both observations and coupled models is underdeveloped." Some recent modeling studies show that the flood hazard is likely to rise in the future and that plausible climate change scenarios result in future increases of both amplitude and frequency of flooding events. Yet, there has been no conclusive and general proof as to how climate change affects the flood behaviour, based on the data observed so far. As climate impact assessment is laden with high uncertainty, its usefulness to practical flood preparedness planning is, at present, very limited.

\section{Acknowledgements}

The work reported in the paper was carried out within the grant no. 6 P 04 E 05520 of the Scientific Research Committee, Republic of Poland.

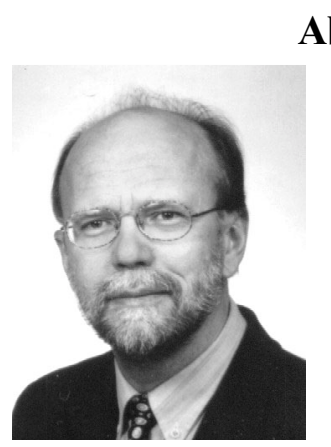

\section{About the Author}

Dr. Zbigniew W. Kundzewicz has been working at the Research Centre of Agricultural and Forest Environment, Polish Academy of Sciences in Poznan, since 1990. He has also been working (part-time) at the Potsdam Institue for Climate Impact Research (PIK) in Potsdam, Germany, since 2001. He has published over 130 papers and several books in hydrology and water resources and serves as Editor of the International Association of Hydrological Sciences and bi-monthly $\mathrm{Hy}$ drological Sciences Journal. In 1987 he was awarded the Tison Prize (IAHS). His recent research interests include sustainable development and water resources systems and impacts of climate on water resources. He can be reached at the Research Centre of Agricultural and Forest Environment, Polish Academy of Sciences, Bukowska 19, 60-809 Poznan, Poland. Email: zkundze@man.poznan.pl, Bukowska 19, 60-809 Poznan, Poland, and Potsdam Institute for Climate Impact Research, 14412 Potsdam, Germany, email: zbyszek@pik-potsdam.de. 
Discussions open until September 1, 2002.

\section{References}

Arnell, N. W. 1999. "Climate Change and Global Water Resources." Global Environ. Change 9: S31-S49.

Berz, G. 2001. "Climatic Change: Effects on and Possible Responses by the Insurance Industry.” In J.L. Lozán, H. Graß1, and P. Hupfer, eds. Climate of the $21^{\text {st }}$ Century: Changes and Risks. Hamburg, Germany: Wissenschaftliche Auswertungen. 392-399.

Bronstert, A., ed. 1996. Hochwasser in Deutschland unter Aspekten globaler Veränderungen. Bericht über das DFG-Rundgespräch am 9. October 1995 in Potsdam, PIK Report No. 17.

Brooks, H. 1992. "The Concepts of Sustainable Development and Environmentally Sound Technology." ATAS Bulletin 7: 19-24.

Engel, H. 1997. "The Flood Events of 1993/1994 and 1995 in the Rhine River Basin." In Destructive Water: Water-caused Natural Disasters, Their Abatement and Control. G.H. Leavesley, H.F. Lins, F. Nobilis, R.S. Parker, V.R. Schneider, and F.H.M. van de Ven, eds. IAHS Publ. No. 239: 21-32.

Environment Agency (U K). 1998. "An Action Plan for Flood Defence." London, United Kingdom.

Galloway, G. E. 1999. "Towards Sustainable Management of River Basins: Challenges for the $21^{\text {st }}$ Century." In Ribamod. River Basin Modeling, Management and Flood Mitigation. Concerted Action. P. Balabanis, A. Bronstert, R. Casale, and P. Samuels, eds. Proceedings of the final workshop, Wallingford, 26-27 February 1998: 235-250. Luxembourg: Office for Official Publications of the European Communities.

Gardiner, J. 1995. "Developing Flood Defence as a Sustainable Hazard Alleviation Measure." In Defence from Floods and Floodplain Management. J. Gardiner et al., eds. Dordrecht: Kluwer: 13-40.

Gilvear, D.J. and A.R. Black. 1999. "Flood-induced Embankment Failures on the River Tay: Implications of Climatically Induced Hydrological Change in Scotland." Hydrological Sciences Journal 44, No. 3: 345-362.

IFRCRCS (International Federation of Red Cross and Red Crescent Societies). 1997. World Disasters Report 1997. Oxford: Oxford University Press.

IFMRC (Interagency Floodplain Management Review Committee). 1994. Sharing the Challenge: Floodplain Management into the $21^{\text {st }}$ Century. A Blueprint for Change. Washington, DC, USA.

IPCC (Intergovernmental Panel on Climate Change). 2001a. Climate Change 2001: Impacts, Adaptation and Vulnerability. Contribution of the Working Group II to the Third Assessment Report of the Intergovernmental Panel on Climate Change. Cambridge: Cambridge University Press.

IPCC (Intergovernmental Panel on Climate Change). 2001b. Climate Change 2001: The Scientific Basis. Contribution of the Working Group I to the Third Assessment Report of the Intergovernmental Panel on Climate Change. Cambridge: Cambridge University Press.
IUCN (International Union for Conservation of Nature). 1991. Caring for the Earth, a Strategy for Sustainable Living. London, England, United Kingdom: IUCN, UNEP and WWF.

Karl, T.R., R.W. Knight, and N. Plummer. 1995. "Trends in Highfrequency Climate Variability in the Twentieth Century." $\mathrm{Na}$ ture 377: 217-220.

Kundzewicz, Z.W. 1997. "Water Resources for Sustainable Development." Hydrological Sciences Journal 42, No. 4: 467480.

Kundzewicz, Z.W. 1999. "Flood Protection - Sustainability Issues.” Hydrological Sciences Journal 44: 559-571.

Kundzewicz, Z.W. 2001. "Some For All, Forever - Sustainable Development and Management of Water Resources." Int. J. Sustain. Dev. World Ecol. 8: 290-298.

Kundzewicz, Z.W, L. Gottschalk, and B. Webb, eds. 1987. Hydrology 2000, IAHS Publ. No. 171, IAHS Press, Wallingford.

Kundzewicz, Z.W. and Z. Kaczmarek. 2000. "Coping with Hydrological Extremes." Water International 25, No. 1: 66-75

Kundzewicz, Z.W. and A. Robson, A., eds. 2000. Detecting Trend and Other Changes in Hydrological Data. World Climate Programme - Water, World Climate Programme Data and Monitoring, WCDMP-45, WMO/TD-No. 1013. Geneva, May 2000.

Kundzewicz, Z.W., K. Szamalek, and P. Kowalczak. 1999. “The Great Flood of 1997 in Poland." Hydrological Sciences Journal 44, No. 6: 855-870.

Kundzewicz, Z.W. and K. Takeuchi. 1999. "Flood Protection and Management: Quo Vadimus?" Hydrological Sciences Journal 44, No. 3: 417-432.

Lins, H.F. and J.R. Slack. 1999. "Streamflow Trends in the United States." Geoph. Res. Letters 26, No. 2: 227-230.

Loucks, D.P. 1994. "Sustainability: What Does This Mean for Us and What Can We Do About It?" Water Resources Planning in a Changing World. Proceedings International UNESCO Symposium, Karlsruhe. Germany 28-30 June 1994. I-3-I-12.

Mansell, M.G. 1997. "The Effect of Climate Change in Rainfall Trends and Flooding Risk in the West of Scotland." Nordic Hydrology 28: 37-50

Newson, M. 1997. Land, Water and Development. Sustainable Management of River Basin Systems $2^{\text {nd }}$ ed. London, England, United Kingdom: Routledge.

Nobilis, F. and P. Lorenz. 1997. "Flood Trends in Austria." In Destructive Water: Water-caused Natural Disasters, Their Abatement and Control. G.H. Leavesley, H.F. Lins, F. Nobilis, R.S. Parker, V.R. Schneider and F.H.M. van de Ven, eds. IAHS Publ. No. 239.

Olsen, J.R., J.R. Stedinger, N.C. Matalas, and E.Z. Stakhiv. 1999. "Climate Variability and Flood Frequency Estimation for the Upper Mississippi and Lower Missouri Rivers." JAWRA: 1509-1522.

Osborn, T.J., M. Hulme, P.D. Jones, and T.A. Basnet. 2000. “Observed Trends in the Daily Intensity of United Kingdom Precipitation." Int. Journal of Climatology 20: 347-364.

Parry M. L., ed. 2000. Assessment of Potential Effects and Adaptations for Climate Change in Europe: The Europe ACA- 
CIA Project. London, England, United Kingdom: Jackson Environment Institute, University of East Anglia.

Pielke, R. A. and M. Downton. 2000. "Precipitation and Damaging Floods. Trends in the United States, 1932-1997." Journal of Climate 13: 3625-3637.

Radziejewski, M., A. Bardossy, and Z.W. Kundzewicz. 2000. "Detection of Change in River Flow Using Phase Randomization." Hydrol. Sci. J. 45, No. 4: 547-558.

Robson, A.J. and D.W. Reed. 1996. "Non-stationarity in UK Flood Records." In Flood Estimation Handbook. Note 25, Wallingford, United Kingdom: Institute of Hydrology, Centre for Ecology and Hydrology.

Takeuchi, K., M. Hamlin, Z.W. Kundzewicz, D. Rosbjerg, and S.P. Simonovic, eds. 1998. Sustainable Reservoir Development and Management. IAHS Publ. No. 251.
Thomas, F.H. 1995. "Principles of Floodplain Management.” In Defence from Floods and Floodplain Management. J. Gardiner et al., eds. Kluwer: 257-270.

Trenberth, K.E. 1998 “Atmospheric Moisture Residence Times and Cycling: Implications for Rainfall Rates and Climate Change." Climatic Change 39: 667-694.

WCED (World Commission on Environment and Development). 1987. Our Common Future (The Brundtland Report). Oxford, United Kingdom: Oxford University Press.

Williams, P.B. 1994. "Flood Control vs Flood Management." Civil Engineering May: 51-54.

WMO. 1995. INFOHYDRO Manual, Hydrological Information Referral Service. Operational Hydrology Report No. 28, WMO-No. 683. 